\title{
Lithium-induced thyrotoxicosis in a patient with treatment-resistant bipolar type I affective disorder
}

\author{
Santhi Chalasani \\ MBBS(Hons) \\ Endocrinology Registrar \\ Katherine A Benson \\ MBBS(Hons), FRACP
Endocrinologist ${ }^{2}$ \\ 1 Royal Prince Alfred Hospital, \\ Sydney, NSW. \\ 2 Concord Repatriation \\ General Hospital, \\ Sydney, NSW. \\ shanth_c@hotmail.com
}

doi: 10.5694/mjal4.00159

\section{Clinical record}

In June 2012, a 19-year-old woman presented to an emergency department with a 2-week history of headaches, lethargy, $2 \mathrm{~kg}$ weight loss and tremor. Her medical history included treatmentresistant bipolar type I affective disorder, subclinical hypothyroidism and polycystic ovarian syndrome. Her medications included lithium carbonate $1250 \mathrm{mg}$ daily, quetiapine $1000 \mathrm{mg}$ daily, chlorpromazine $200 \mathrm{mg}$ daily, cyproterone acetate/ethinyloestradiol $2 \mathrm{mg} / 35 \mu \mathrm{g}$ daily, cholecalciferol $1000 \mathrm{IU}$ daily, and lorazepam $1 \mathrm{mg}$ at night for insomnia as needed. She had not been given an iodine-containing contrast medium, and she reported that she had not been taking thyroxine and that she had not ingested excessive amounts of iodine or kelp. She had no history of ocular symptoms. Her paternal grandmother had had a thyroidectomy.

In April 2010 (several months after commencing lithium therapy), she had developed subclinical hypothyroidism. Results of serum tests showed an elevated TSH level of $5.94 \mathrm{mIU} / \mathrm{L}$ (RI, 0.4-3.5 mIU/L) and a normal $\mathrm{FT}_{4}$ level of $12.8 \mathrm{pmol} / \mathrm{L}$ (RI, 9.0$19.0 \mathrm{pmol} / \mathrm{L}$ ). This had resolved spontaneously within months.

On presentation at the emergency department, the patient was afebrile and tachycardic with a heart rate of 120 beats/min. She had a small, diffuse, non-tender goitre without bruit. Lid lag and tremor were evident. Results of a general examination were otherwise unremarkable.

Results of initial serum tests showed hyperthyroidism - an elevated $\mathrm{FT}_{4}$ level of $63.6 \mathrm{pmol} / \mathrm{L}(\mathrm{RI}, 12.0-22.0 \mathrm{pmol} / \mathrm{L})$ and a suppressed $\mathrm{TSH}$ level of $0.01 \mathrm{mIU} / \mathrm{L}(\mathrm{RI}, 0.4-4.0 \mathrm{mlU} / \mathrm{L})$. Results of thyroid antibody tests were negative (and remained so on repeat testing until February 2013). Results of serial thyroid function tests and thyroid antibody tests are summarised in the Table. The patient's renal function and results of a full blood examination were normal. A technetium thyroid scan showed no significant tracer uptake, a result that is consistent with thyroiditis.

The patient was prescribed propranolol therapy (10 mg three times a day). She continued taking lithium therapy and was discharged 2 days later. Within 2 days of discharge, her thyroid function had improved markedly and her serum lithium level was $0.75 \mathrm{mmol} / \mathrm{L}$, which is within the therapeutic range $(0.50-1.20 \mathrm{mmol} / \mathrm{L})$. In August 2012, repeat thyroid function tests showed hypothyroidism, so she was prescribed thyroxine $50 \mu g$ daily. The treating psychiatrist later prescribed clozapine therapy. In December 2012, she was taking clozapine $150 \mathrm{mg}$ in the morning and $200 \mathrm{mg}$ at night, and weaning from lithium was initiated.

\begin{tabular}{|c|c|c|c|c|c|c|c|c|}
\hline \multirow[b]{2}{*}{ Date } & \multicolumn{8}{|c|}{ Serum level (RI) } \\
\hline & TSH (mlU/L) & $\mathrm{FT}_{4}(\mathrm{pmol} / \mathrm{L})$ & $\mathrm{FT}_{3}(\mathrm{pmol} / \mathrm{L})$ & $\operatorname{Tg}(\mu g / L)$ & $\begin{array}{l}\text { TPOAb } \\
(\mathrm{kIU/L)}\end{array}$ & $\begin{array}{l}\text { TgAb } \\
(\mathrm{kIU/L})\end{array}$ & $\begin{array}{l}\text { TSHRAb } \\
\text { (IU/L) }\end{array}$ & $\begin{array}{l}\text { Lithium } \\
\text { (mmol/L) }\end{array}$ \\
\hline 15 Oct 2008 & $1.43(0.4-3.7)$ & $14.2(7.3-22.1)$ & $4.6(2.5-7.3)$ & - & $<35(<35)$ & $<40(<40)$ & - & - \\
\hline 30 Apr 2010 & $5.94(0.4-3.5)$ & $12.8(9.0-19.0)$ & - & - & $<35(<35)$ & $<40(<40)$ & - & - \\
\hline 06 Aug 2010 & $2.75(0.4-3.5)$ & $14.3(9.0-19.0)$ & $3.5(2.6-6.0)$ & - & $<35(<35)$ & $<40(<40)$ & - & $1.26(0.5-1.2)$ \\
\hline 22 Mar 2012 & $3.24(0.4-3.5)$ & 10.9 (9.0-19.0) & - & - & - & - & - & $0.64(0.5-1.2)$ \\
\hline 13 Jun 2012 & - & - & - & - & - & - & - & $0.72(0.5-1.2)$ \\
\hline 14 Jun 2012* & $0.01(0.4-4.0)$ & $63.6(12.0-22.0)$ & - & $1180(<55)$ & $<35(<35)$ & $<40(<40)$ & $<1.0(<2.0)$ & - \\
\hline 18 Jun 2012 & $0.01(0.4-3.5)$ & $27.8(9.0-19.0)$ & $13.0(2.6-6.0)$ & $1570(<30)$ & $<35(<35)$ & $<40(<40)$ & $<1.0(<1.0)$ & $0.75(0.5-1.2)$ \\
\hline 21 Aug 2012 & $6.05(0.3-4.2)$ & $7.0(12.0-25.0)$ & - & - & - & - & - & - \\
\hline 01 Dec 2012 & $3.64(0.4-4.0)$ & $14.2(12.0-22.0)$ & - & - & - & - & - & - \\
\hline 15 Feb 2013 & - & - & - & - & $<10(<35)$ & $<20(<40)$ & - & - \\
\hline
\end{tabular}

ong-term lithium therapy is frequently used to treat psychiatric conditions and has been associated with a variety of thyroid abnormalities. The effects of lithium on the thyroid gland are largely inhibitory. Lithium hinders the action of thyroid-stimulating hormone (TSH) and interferes with thyroid hormone synthesis through the inhibition of adenylate cyclase. Lithium decreases thyroid iodine release, reduces iodide organification and increases thyroid iodide content. $^{1}$
Lithium prolongs the retention of radioiodine in the thyroid gland. In patients treated with lithium, elevated and diffuse uptake on a radioiodine scan can be misinterpreted as a sign of Graves disease. However, this was not the case in our patient, who had a technetium scan. Other explanations for low tracer uptake on the technetium scan include recent iodine ingestion or surreptitious or inadvertent thyroxine ingestion. Our patient had not been ingesting iodine and her thyroglobulin levels were high, not low, which excluded the possibility 
Lessons from practice

- Lithium has profound effects on thyroid physiology - goitre, hypothyroidism and subclinical hypothyroidism are common.

- Although the mechanisms are unclear, there is increasing recognition that lithium is associated with thyrotoxicosis and induction of autoimmunity.

- In cases of lithium-induced thyroiditis, conservative management with regular follow-up is indicated because most patients subsequently develop hypothyroidism.

- Thyroid function tests and tests for thyroid antibodies should be performed before lithium therapy is started and performed regularly during lithium therapy.

of thyroxine ingestion. The decline in free thyroxine was more rapid than expected, given the usual half-life of thyroxine. This may be partly due to the shortened halflife of free thyroxine in the context of hyperthyroidism, but laboratory error is also possible.

In patients treated with lithium, goitre is the most common thyroid abnormality. ${ }^{2}$ Reported prevalence ranges from $4 \%{ }^{3}$ to $51 \%{ }^{4}$ Goitre is thought to be due to the inhibitory effects of lithium causing increased TSH concentrations. Hypothyroidism and subclinical hypothyroidism are also common. In a study of 274 patients who were taking long-term lithium therapy, the prevalence of hypothyroidism was $10.3 \% .^{5}$ In the same study, only one case of thyrotoxicosis was observed. In another study, no cases of thyrotoxicosis were observed over 768 patient-years, ${ }^{6}$ suggesting that lithium-induced hyperthyroidism is extremely rare.

Results from a retrospective review of medical records suggest that a significant proportion of patients with lithium-associated thyrotoxicosis have - as seen in our patient - transient, painless thyroiditis. ${ }^{7}$ Of 19 patients with lithium-associated thyrotoxicosis, 13 were diagnosed with silent thyroiditis, five with Graves disease and one with toxic nodular goitre. In patients receiving lithium, there was an increased relative prevalence of silent thyroiditis versus Graves disease and a greater than expected incidence of silent thyroiditis. A possible explanation for our patient's presentation may have been a coincidental episode of painless silent thyroiditis unrelated to lithium therapy.

Most cases of lithium-associated thyroiditis occur while patients are taking lithium ${ }^{7,8}$ and while the serum lithium level is in the therapeutic range. ${ }^{7}$ In a review of 11 cases of lithium-associated silent thyroiditis, the duration of therapy before the development of thyrotoxicosis ranged from 6 days to 15 years. ${ }^{8}$ However, in some cases, thyrotoxicosis occurred 4 days to 5 months after withdrawal of lithium therapy. ${ }^{7,8}$ A review of cases of lithium-induced thyroiditis from 1978 to 1995 showed that most patients subsequently developed hypothyroidism, as seen in our patient; in the remainder, thyroiditis remitted spontaneously. ${ }^{7}$ This was independent of the decision to continue or withdraw lithium therapy. Thus, the decision to discontinue lithium therapy in the context of thyroid dysfunction should be made with attention to the severity of the underlying psychiatric disorder.

The mechanism of lithium-induced thyrotoxicosis is not well understood. Some authors have suggested that lithium, by expanding the intrathyroidal iodide pool, may precipitate thyrotoxicosis in patients with a genetic predisposition to Graves disease or thyroid nodules. ${ }^{9}$ Autoimmunity may play a significant role in lithium-induced thyroiditis. In a case-control study of patients with primary affective disorders, eight of 40 who were receiving lithium tested positive for thyroid antibodies, compared with three of 40 who were receiving drugs other than lithium. Patients receiving lithium had significantly reduced numbers of suppressor and/or cytotoxic T cells, and increased B cell activity was seen in patients receiving lithium and those receiving drugs other than lithium. ${ }^{10}$ Painless thyroiditis may also be the result of a direct toxic effect of lithium on the thyroid, as occurs in amiodarone-induced toxic thyroiditis. ${ }^{7}$ This seems the likely mechanism in our patient, in whom results of tests for thyroid antibodies remained negative.

Lithium-induced thyroiditis can usually be managed conservatively, with regular monitoring of thyroid function. The role of steroids is unclear and the potential for exacerbation of psychiatric disease must be considered. While cholestyramine sometimes has a role in treating thyroiditis, its role in lithium-induced thyroiditis is unclear. Patients with lithium-induced Graves disease should be treated with carbimazole, and radioiodine therapy and thyroidectomy should be considered. In patients with toxic nodular goitre, thyroidectomy may be indicated. ${ }^{2}$

\section{Competing interests: No relevant disclosures.}

1 Berens SC, Bernstein RS, Robbins J, Wolff J. Antithyroid effects of lithium. J Clin Invest 1970; 49: 1357-1367.

2 Kibirige D, Luzinda K, Ssekitoleko R. Spectrum of lithium induced thyroid abnormalities: a current perspective. Thyroid Res 2013; 6: 3.

3 Schou M, Amdisen A, Eskjaer Jensen S, Olsen T. Occurrence of goitre during lithium treatment. Br Med J 1968; 3: 710-713.

4 Bocchetta A, Bernardi F, Pedditzi M, et al. Thyroid abnormalities during lithium treatment. Acta Psychiatr Scand 1991; 83: 193-198.

5 Kirov G, Tredget J, John R, et al. A cross-sectional and a prospective study of thyroid disorders in lithium-treated patients. J Affect Disord 2005; 87 : 313-317.

6 Bocchetta A, Mossa P, Velluzzi F, et al. Ten-year follow-up of thyroid function in lithium patients. J Clin Psychopharmacol 2001; 21: 594-598.

7 Miller KK, Daniels GH. Association between lithium use and thyrotoxicosis caused by silent thyroiditis. Clin Endocrinol (Oxf) 2001; 55: 501-508.

8 Dang AH, Hershman JM. Lithium-associated thyroiditis. Endocr Pract 2002; 8: $232-236$.

9 McDermott MT, Burman KD, Hofeldt FD, Kidd GS. Lithium-associated thyrotoxicosis. Am J Med 1986; 80: 1245-1248.

10 Wilson R, McKillop JH, Crocket GT, et al. The effect of lithium therapy on parameters thought to be involved in the development of autoimmune thyroid disease. Clin Endocrinol (Oxf) 1991; 34: 357-361. 